\title{
Research on Management Conflict Matrix of Cross-border E- commerce Logistics Based on TRIZ Model
}

\author{
Junbing Liu ${ }^{1}$, Simei Ruan ${ }^{1}$, and Yunji Huang ${ }^{1}$ \\ ${ }^{1}$ Economics \& Management Department, Maoming Technical No. 232, North Wenming Road, Maoming City, Guangdong Pr. China
}

\begin{abstract}
Cross-border E-commerce and international logistics are national key projects. International logistics is more important as Cross-border E-commerce becomes the main form of international trade. Based on the features of Cross-border E-commerce logistics, this paper selects Guangdong, where developing factors of Cross-border E-commerce industry and international logistics industry are relatively complete, as the representative research site. Questionnaires are distributed to 503 researchers from Cross-border E-commerce companies and universities in Guangdong province. Researchers use SPSS to analyze the reliability and validity of the data, and adopt the TRIZ theory to construct a logistics conflict matrix. The positive factor is inversely proportional to the negative factor variable. On the one hand, the ideal state of logistics weakens as the negative factor of logistics increases; on the other hand, the ideal state of logistics strengthens as the positive factor of logistics increases.
\end{abstract}

\section{Introduction}

As a new form of international trade, Cross-border Ecommerce highly depends on logistics. The research of how international logistics facilitate Cross-border Ecommerce is critical for understanding the operating process of cross-border logistics in China. As the pioneers of Cross-border E-commerce, logistics companies and the manufacturing industry in the Pearl River Delta region have played very important roles in promoting the transformation of foreign trade companies into Crossborder E-commerce. The manufacturing and logistics industries have achieved tremendous development by providing a great deal of raw material to Cross-border Ecommerce Companies. The coordinated development contributes to the virtuous circle in economy. Based on the theory of efficiency and cost optimization, Cross-border E-commerce companies hope to reduce shipment costs while improving logistics efficiency. According to the related documents issued by the government in 2019 and 2020 , our country pays close attention to the development of the distribution industry in an all-round way and the prosperity of trade at home and abroad. The factors such as efficiency, coverage rate, and service, decide whether we can develop Cross-border E-commerce with high quality. However, the backward technological innovation in distribution industry and the low logistics output constraints Cross-border E-commerce in our country. The priority is to increase the coverage and output rate of logistics, as well as to improve the customer service and reduce the shipment costs.

\section{Literature review}

In recent decade, there is a great deal of research on the application of TRIZ theory in management with some valuable outcomes. The research mainly focuses on three domains. Firstly, it explores the technology innovation in production. Xu Feng (2010) stated in the empirical analysis of the Samsung Group's application of innovative methods. Samsung introduced the TRIZ theory in 1998 and applied TRIZ to all areas of the product manufacturing process, bringing technological innovation and enabling Samsung to become the industrial leader. The brand value of Samsung surpassed that of Sony in 2006, and was assessed as the fastest growth for the five consecutive years in 2007. Samsung promoted the TRIZ theory and has gone through three stages of preparation, dissemination and acceleration. It has successively established a TRIZ promotion department, formulated a training plan for employees, practiced TRIZ theory in production. It has also established a core patent protection system and incentive mechanism. It successfully introduced innovative methods such as TRIZ, which brought continuous technological innovation to Samsung, reduced research and development costs, and obtained huge economic benefits. Secondly, it investigates the method innovation in management. Zhang Dongsheng (2015) discussed in the book TRIZ-based management innovation methods that corporate management adopts the TRIZ method to discover conflicts in the enterprise, determine conflict elements, create conflict matrix, and help companies solve the dilemma by analyzing conflict factor matrix data. 
From the literature review, we know that there is a few research in the application of TRIZ theory in social science. Firstly, many scholars think that TRIZ theory could only be applied in natural science. Product development factors have nothing to do with social science research factors. Secondly, that TRIZ theory is adopted in management innovation is in a macro way. It is seldom adopted in cross-industry business, let along Cross-border E-commerce. Cross-border E-commerce emerged 7 years ago and has been developing quickly. It has become the main form of foreign trade and an important source of foreign exchange in our country. However, Cross-border logistics is a hindrance to Crossborder E-commerce development. The research of adopting TRIZ theory in building a foreign logistics conflict management matrix will have practical significance.

\section{Data description and empirical analysis}

Zhang Dongsheng(2015) says that TRIZ theory can predict the law of development while making inventions and technological innovations. It plays a role in solving technical problem and developing innovative technology. When there are contradictions between technology and theory, contradictions can be eliminated to ensure the sustainable development of technology by using TRIZ. This study uses TRIZ theory to determine relevant research factors about Cross-border logistics. Questionnaires are distributed to 503 researchers from Cross-border E-commerce companies and universities in Guangdong province, of which 366 are valid. The research process includes distribution, recycling, screening, statistical analysis of questionnaires

Table1. Analysis of research data

\begin{tabular}{|l|l|l|l|}
\hline Factors & Sample size & SD & Mean \\
\hline Local policy & 366 & 0.91 & 1.74 \\
\hline Logistics system & 366 & 1.09 & 3.21 \\
\hline Cost & 366 & 1.08 & 1.88 \\
\hline Link & 366 & 1.79 & 2.81 \\
\hline Efficiency & 366 & 1.05 & 3.16 \\
\hline Coverage & 366 & 1.07 & 3.15 \\
\hline Traceability & 366 & 1.07 & 3.10 \\
\hline Information sharing & 366 & 1.08 & 3.15 \\
\hline Personalization & 366 & 1.07 & 3.17 \\
\hline Goods procurement & 366 & 1.28 & 3.27 \\
\hline Customs clearance & 366 & 1.79 & 3.16 \\
\hline
\end{tabular}

The intermediate value of the mean is 3 . The smaller the mean, the higher the satisfaction. The smaller the standard deviation, the higher the polymerization degree of the selected results. The larger the standard deviation, the higher the dispersion of the selected results. From Table 1, we know that companies are relatively satisfied with local policies and international logistics links, and international shipment costs are acceptable. However, they are not satisfied with the overall logistics services, such as logistics efficiency, international logistics coverage, cargo tracking capabilities, logistics information sharing, personalized services, etc. The most dissatisfied is goods procurement.

Reliability, the same as credibility, refers to the degree of consistency of the results obtained when the same method is used to repeatedly measure the same object (Mikhalkina \& Cabantous, 2015).

Table2. Research reliability analysis

Cronbach Reliability analysis

\begin{tabular}{|c|c|c|c|}
\hline Name & $\begin{array}{l}\text { Corrected item- } \\
\text { total correlation (CIT } \\
\text { C) }\end{array}$ & $\begin{array}{l}\text { Item Deleted Cro } \\
\text { nbach's Alpha }\end{array}$ & $\begin{array}{l}\text { Cronbac } \\
\mathrm{h} \alpha\end{array}$ \\
\hline Local policy & 0.281 & 0.898 & \multirow{10}{*}{0.892} \\
\hline Logistic system & 0.731 & 0.875 & \\
\hline Goods procurement & 0.713 & 0.877 & \\
\hline Link & 0.128 & 0.917 & \\
\hline Customs clearance & 0.678 & 0.879 & \\
\hline Information sharing & 0.790 & 0.871 & \\
\hline Logistics efficiency & 0.724 & 0.875 & \\
\hline $\begin{array}{l}\text { International logisticsco } \\
\text { verage }\end{array}$ & 0.821 & 0.871 & \\
\hline Traceability & 0.830 & 0.869 & \\
\hline Logistics personalization & n 0.871 & 0.866 & \\
\hline
\end{tabular}

Illustration: When $\alpha$ coefficient is higher than 0.8 , it is of high reliability, and the survey data is valid.

Validity, refers to the degree to which a measurement can be made by using a measurement tool or means. The validity of the research can be guaranteed by verifying the design of the research process and controlling each research process based on the characteristics of the survey (The SPSSAU project,2020).

Table3. Inspection of KMO

Inspection of KMO and Bartlett

\begin{tabular}{lll}
\hline KMO & Approximate chi square & 3038.291 \\
\cline { 2 - 3 } $\begin{array}{l}\text { Bartlett's spher } \\
\text { icity test }\end{array}$ & $\frac{d f}{p}$ & 55 \\
\cline { 2 - 3 } & $p$ & 0.000 \\
\hline
\end{tabular}

Table 4 Research validity analysis

Result of validity analysis

\begin{tabular}{llll}
\hline \multirow{2}{*}{ Name } & \multicolumn{2}{l}{ Factor loading coefficient } & Communalitie \\
\cline { 2 - 4 } & Coefficient 1 & Coefficient 2 & \\
\hline Local polity & 0.484 & 0.140 & 0.254 \\
\hline Logistics system & 0.817 & 0.218 & 0.715 \\
\hline Goods procurement & 0.802 & 0.218 & 0.690 \\
\hline Link & 0.037 & 0.842 & 0.710 \\
\hline Customs clearance & 0.844 & 0.124 & 0.728 \\
\hline Information sharing & 0.891 & 0.079 & 0.799 \\
\hline Logistics efficiency & 0.859 & 0.080 & 0.744 \\
\hline International logisticscoverage & 0.897 & 0.062 & 0.808 \\
\hline Traceability & 0.878 & 0.112 & 0.784 \\
\hline personalization & 0.894 & 0.069 & 0.805 \\
\hline
\end{tabular}


Characteristic root(before rotation) 6.390 1.057

\begin{tabular}{|c|c|c|c|}
\hline $\begin{array}{l}\text { Explanation rate of variance } \% \text { (bef } \\
\text { ore rotation) }\end{array}$ & $58.089 \%$ & $9.609 \%$ & - \\
\hline $\begin{array}{l}\text { Accumulated explanation rate of } \mathrm{v} \\
\text { ariance } \% \text { (before rotation) }\end{array}$ & $58.089 \%$ & $67.698 \%$ & - \\
\hline Characteristic root(after rotation) & 6.191 & 1.256 & - \\
\hline $\begin{array}{l}\text { Explanation rate of variance } \% \text { (afte } \\
\mathrm{r} \text { rotation) }\end{array}$ & $56.280 \%$ & $11.418 \%$ & - \\
\hline $\begin{array}{l}\text { Accumulated explanation rate of } \mathrm{v} \\
\text { ariance } \% \text { (after rotation) }\end{array}$ & $56.280 \%$ & $67.698 \%$ & - \\
\hline KMO & 0.934 & & - \\
\hline Bartlett's sphericity test & 3038.291 & & - \\
\hline$d f$ & 55 & & - \\
\hline$p$ & 0.000 & & - \\
\hline
\end{tabular}

If the numbers in the table are colored: blue means the absolute Factor loading coef ficient is greater than 0.4 , red means the degree of commonality is less than 0.4

Validity analysis is used to study the plausibility of quantitative data (especially attitude scale questions).On the one hand, KMO is analyzed. If the value is higher than 0.8 , it indicates that the validity is high. On the other hand, the corresponding relationship between the item and the factor is analyzed. If the corresponding relationship is basically consistent with the research psychological expectation, it shows that the validity is good. If the KMO community is less than 0.4 , and the corresponding relationship between the item and the factor is seriously deviated, the research team believes that there may be social environmental factors.

\section{Theoretical model construction}

\subsection{TRIZ conflict matrix}

TRIZ theory is a method that discovers and solves problems based on the principle of knowledge system. It is a method that can effectively describe the development of new technologies and new systems, and can elaborate a series of evolution processes of technologies and systems. TRIZ was originally used to solve innovative problems. It provides an effective model for innovative and complex contradictions.

This article uses TRIZ theory combined with SPSS data analysis to conduct empirical research on the factor weights of Cross-border E-commerce logistics, and build a general linear model. The model is as follows:

Conflict matrix is constructed based on factors as local policy, logistics system, cost, links, efficiency, coverage, traceability, information sharing, personalization, goods procurement, customs clearance.

\begin{tabular}{|c|c|c|c|c|c|c|c|c|c|c|c|c|}
\hline & \multirow{2}{*}{ Factor } & \multicolumn{11}{|c|}{ Affected parameters (should be kept) k } \\
\hline & & $\begin{array}{l}\text { Local } \\
\text { policy }\end{array}$ & $\begin{array}{l}\text { Logistics } \\
\text { system }\end{array}$ & Cost & Links & Efficiency & Coverage & Traceability & $\begin{array}{c}\text { Information } \\
\text { sharing }\end{array}$ & Personalization & $\begin{array}{c}\text { Goods } \\
\text { procurement }\end{array}$ & $\begin{array}{l}\text { Customs } \\
\text { clearance }\end{array}$ \\
\hline \multirow{11}{*}{$\begin{array}{c}\text { Parameter } \\
\text { need to } \\
\text { be } \\
\text { improved } \\
\text { j }\end{array}$} & Local policy & + & 11. 20 & -- & -- & -- & 3. 1120 & 2.5 & 2. & -- & 3. 11 . & 20.25 \\
\hline & Logistics system & 3.11 & + & 11.5 & 25.34 .6 & 2. 5.7 & 11. 22 & 3. 19. & 32.4 & 6 & 4. 38 & 5.7 \\
\hline & Cost & 3 & 2.5 & + & 5.21 .23 & 4. & 22. 12. & 38.40 & 38 & 20 & 5.11 & 13 \\
\hline & Links & 25 & 3. 12 . & 5.23 & + & 3. & 25 & 2.7 & 13. & 8. 13 & 23. & 23 \\
\hline & Efficiency & -- & 5.11. & 4. & 2. 25 & + & 38 & 20 & 38 & 6 & 20 & 12. 20 \\
\hline & Coverage & 4. 9.11 & 9. 22.25 . & 22. 12. & 25 & 21 & + & 25 & 12. & 13. 22 & 5 & -- \\
\hline & Traceability & 2. 10 & 3. 11 & 38.40 & 2. 12 & 20 & 11 & + & 22 & 6. 38 & 20 & 11 \\
\hline & $\begin{array}{c}\text { Information } \\
\text { sharing }\end{array}$ & 2. 24 & 4. 32 & 38 & 13. & 22 & 9 & 32 & + & 6 & 38 & 7 \\
\hline & Personalization & -- & 6.13 & 20 & 8.13 & 4 & 22 & 4 & 4 & + & 5 & 11 \\
\hline & $\begin{array}{c}\text { Goods } \\
\text { procurement }\end{array}$ & 40 & 32.4 & 5.11 & 23. & 13 & 11 & 23 & 3 & 38 & + & 4. 9.11 \\
\hline & $\begin{array}{c}\text { Customs } \\
\text { clearance }\end{array}$ & 19. 25 & 5.20 & 13 & 21 & 12. 20 & -- & 23 & 21 & 11. 23 & 2 & + \\
\hline
\end{tabular}

There will be many solutions to problems according to the conflict matrix. Managers need to select the factors that need to be improved under specific situation. Suppose Y

is a general solution set, $\mathrm{Y}_{i}$ is No. $i$ original understanding, then the general solution set $\mathrm{Y}$ can be expressed as

$$
\mathrm{Y}=\left\{Y_{1}, Y_{2}, \cdots, Y_{n-1}, Y_{n}\right\}(i=1,2, \cdots, n)
$$

An original understanding can also correspond to more than one lower or higher level solution, or it can also be understood that each original understanding is

composed of at least one more refined original understanding. So it is a set composed of multiple solutions, which can be written as
The formula can be a combination of one or several solutions.

The conflicts in management are more complicated, and the management conflicts are more intangible and abstract. The management innovation method based on conflict resolution is to describe the problems as pairs of conflicts, which form a conflict matrix , and then find out the technical parameters and give the management parameters according to the matrix. Assuming that the management parameters are $(\mathrm{j}=1,2,3, \ldots \mathrm{m})$, and $m$ is the number of management parameters. In the conflict matrix, negative parameters are in the vertical direction and positive parameters are in the horizontal direction. The negative parameters are expressed as a matrix of $m$ rows and 1 column, which is expressed as 


$$
C_{m 1}=\left(\begin{array}{c}
C_{11} \\
C_{21} \\
\vdots \\
C_{m 1}
\end{array}\right)
$$

The parameters in the horizontal direction is expressed as a matrix of 1 row and $m$ columns, which is expressed as

$$
C_{1 m}=\left[C_{11}, C_{12}, \cdots, C_{1 m}\right]
$$

Multiply by it to form a matrix with $\mathrm{m}$ rows and $m$ columns, which is the mathematical formula for managing conflict matrix

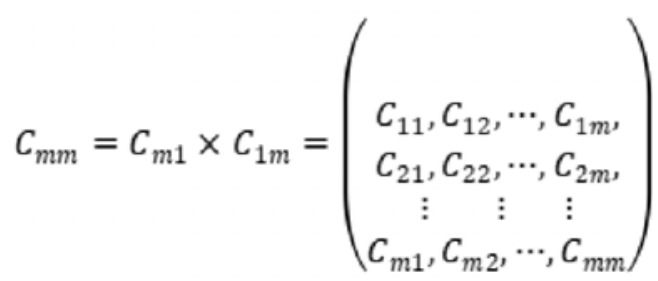

Any element in the conflict matrix in Table 5 represents a pair of conflicts in Row $j$ and Column $k$, indicating that the corresponding conflict solution is a solution set with 0-3 solutions. However, in actual situations there may be more solutions. In a factor conflict, the factors are variables. On the one hand, the ideal state of logistics weakens as the negative factor of logistics increases. On the other hand, the ideal state of logistics strengthens as the positive factor of logistics increases.

$$
\mathrm{I}=\frac{\sum U F}{\sum H F}
$$

I represents the idealization level of logistics, $\sum^{\sum F}$ is the sum of positive factors, and $\sum_{H F}$ is the sum of negative factors. The ideal state of logistics is proportional to the change of the positive factor and inversely proportional to the change of the negative factor. In management, negative factors can be understood as the costs and harms, while positive factors can be understood as the benefits. The idealized state of logistics can be expressed as

$$
\mathrm{I}=\frac{\sum B}{\sum E+\sum H}
$$

$B$ stands forbenefit, $E$ for cost, and $H$ for hazard. On the one hand, costs include shipment costs, shipping time, excessive logistics links, etc. On the other hand, hazards include packaging waste and transportation emissions, etc. The ideal logistics model after segmentation is

$$
\mathrm{I}=\alpha \frac{\sum F_{i} Q_{i}}{\sum C_{j}+\sum \beta_{k} H_{k}}
$$

F represents NO. $i$ positive factor function, $\mathrm{Q}_{i} \quad$ No. $i$ positive function quality. $\mathrm{C}_{\mathrm{j}}$ represents cost and time No.j which incur to realize the forward function. $\mathrm{H}_{k}$ stands for No. $k$ hazard. $\alpha$ and $\beta_{k}$ represent the harm coefficient, and $\beta_{k}$ is the harm coefficient of No. $k$ negative factors

\section{Conclusion}

This article uses TRIZ theory combined with SPSS data analysis to conduct empirical research on the factor weights of cross-border e-commerce logistics, and build a factors conflict matrix. From the research, we know that Logistics costs and efficiency restrain the development of Cross-border E-commerce, while coverage, information sharing and personalization facilitate the growth of logistics. Local policy, customs clearance and traceability have little effect. It is worth noting that when the logistics efficiency changes in both directions, the logistics cost also changes in both directions. That is, Cross-border Ecommerce companies are using high shipment costs to strive for efficiency, so as to seize overseas markets and improve customer experience satisfaction. Compared to local policy, economic variables are more important in promoting Cross-border E-commerce logistics. Therefore, when developing international logistics, it should not confine to one factor. What the market needs are policies which could enhance the overall economic development of the city, such as the rationalization of the industrial structure, the upgrading of manufacturing industry, and the balanced development of the service industry.

\section{Acknowledement:}

Fund project: Research on Constructing the Fourth Party Logistics System Model of Foreign Trade Based on TRIZ Method; Study on the Communicative Discourse of Crossborder E-commerce from the Perspective of Pragmatics from Maoming Municipal Science and Technology Bureau

\section{Reference:}

1. Ying Bai, The influence of technological innovation and accumulation of circulation industry on Industrial Development: mechanism and demonstration. J. Journal of Commercial Economics 2020(4)

2. Feng Xu, An empirical analysis of Samsung Group's application of innovative methods. J. Science \& Technology Progress and Policy,2010,27(4).

3. Huijun Zhao, Application and promotion of TRIZ innovation method and its problems. J. Science \& Technology Vision. 2020（20）176-177

4. Dongsheng Zhang, Wang Wenfu, Shun Jianguang, Research trend of TRIZ theory from the perspective of management. J. Contemporary Economy \& Management 2020, 1 ( 42-1) 14-21

5. Ai Hang, Research on Influencing Factors of TRIZ training effect. D. Journal of Hebei Univers, 2015.

6. SAV R ANSKY S D. Engineering of creativity: introduction to TRIZ methodology of inventive problem solving. J. CRC Press, 2000.

7. Hui Jing, Zhijian Jia, Research on solution mode of complex management problems based on TRIZ. 
J. Science of Science and Management of S.\& T., 2005, 26( 11): 155 - 159 .

8. Shunbing Wang, Xiaodong Pan, The method of technological innovation and the cultivation of enterprise's independent innovation ability. J. Science and Technology Management Research, 2010,30(4)

9. Mikhalkina T, Cabantous L. Business model innovation: how iiconic business models emerge in business models and modeling. M. Emerald Group Publishing Limited. 2015: 59 - 95.

10. The SPSSAU project (2020). SPSSAU. (Version 20.0). Retrieved from https://www.spssau.com.

11. Eisinga R, Te Grotenhuis M, Pelzer B. The reliability of a two-item scale: Pearson, Cronbach, or SpearmanBrown?. J. International Journal of Public Health, 2013, 58(4):637-642.

12. The SPSSAU project (2020). SPSSAU. (Version 20.0). Retrieved from https://www.spssau.com.

13. Chung R H, Kim B S, Abreu J M. Asian American multidimensional acculturation scale: development, factor analysis, reliability, and validity. J. Cultur Divers Ethnic Minor Psychol, 2004, 10(1):66-80.

14. Jun Zhou, Questionnaire data analysis - six kinds of analysis ideas to crack SPSS. M. Publishing House of Electronics Industry, 2017.

15. Dongsheng Zhang, Management innovation method based on TRIZ. M. China Machine Press. 2015.2 